\title{
Correspondence
}

\section{The Approval Exercise}

Dear Sirs

As I have recently been involved in the College's Approval Exercise as a Panel member, I was particularly interested to read Paul Bridges' article, 'The Trials of the Convener of an Approval Team' (Bulletin, August 1982, 6, 132-34). I recognize in that account a number of similar experiences and feelings, but it is from the standpoint of a Senior Registrar on a visiting team that I would like to put forward the following views.

Each College Division has a Convener who organizes the Approval Team for any particular visit. The Team is made up of the Convener and two other members, one of whom may be a Senior Trainee. The Senior Trainee's name is taken from a list, supplied by the Junior to the College Divisions. At present the Convener may decide to include a Senior Registrar or may complete the Team with two further Consultant members. A recent survey by Philip Thomas (Bulletin, July 1982, 6, 124-25) suggests almost half of visiting panels do not include a Senior Trainee. My own view is that Trainee membership of the Approval Team should not be discretionary in this way, but should be an accepted and necessary feature of all Approval exercises. A Senior Registrar in this situation not only has an important representative function but, I feel, can make a unique contribution to the Approval exercise.

One of the main tasks of the team is to interview the SHOs/Registrars, as it is they who are being trained. This can be a delicate operation as some trainees see the Approval Exercise in terms of possible threat to their own careers. Even when assured that any alteration in Approval status for the hospital will not affect their personal training recognition by the College, there remains a reticence to air criticisms in front of outsiders. This may be because of fear, but more commonly loyalty is the reason. During my visits the Juniors were interviewed by the whole team and then by myself either singly or in groups. I found that the trainees were more likely to be forthcoming in discussion with the SR panel member than when consultant panel members were present. This is hardly surprising for an SR will recently have been at a similar stage in training.

There are other benefits: I found the informality of the meetings stimulated a two-way interchange of views, ideas and information. Training is not a passive process, and learning how trainees from other areas can help themselves in terms of organization and education can be invaluable. These meetings made me more aware of the function of a Senior Registrar in this process, particularly in the periphery. The SR is a little like an older sibling, accessible for informal discussion and near enough to the examination system to provide practical guidance.
Broadening the base of opinion included in the team may have advantages. This appears to be particularly relevant when considering the sometimes conflicting pressures of educational and service needs. An SR is more likely to perceive this issue from the point of view of trainees' needs, whereas a consultant member of the team is more likely to identify with the position of a colleague organizing a service and the practical difficulties this entails. The Senior Registrar and Consultant members therefore can provide a much needed counterbalance for each other when assessing a hospital for Training Approval and making recommendations.

I have discussed the contribution of an SR to the approval exercise, but I also feel that being a member of a visiting team provided me with a very useful educational experience. It forced me to think about the practical problems involved in the production of a relevant and comprehensive training programme. I have been given the opportunity to meet trainees from other areas and been made more aware of the Senior Registrar's role in providing a focal point for trainees and their needs.

I am not sure why there is not a Senior Trainee on every visit. Maybe it's because the Approval Exercise can stir up many emotions and when there are difficult areas to discuss the attitude is: 'not in front of the Juniors'. Whilst this is understandable, as all psychiatrists know, if there are problems to be discussed in a family, everyone needs to be there. After all, most of us will hopefully be 'parents' one day.

Royal Victoria Infirmary,

STEPHEN Frost Newcastle upon Tyne

\section{DeAR Sirs}

It was with great interest that I read Dr P. Bridges' article (Bulletin, August 1982, 6, 132-34), as it provided a valuable insight into the workings of a Royal College Approval Team.

While agreeing that, of course, this exercise must be carried out in order to try and maintain and improve the standard of psychiatric training, I do sometimes feel that the recommendations made, concerning increase in staff, improvement of facilities, etc., are quite unrealistic in the present economic climate. I have seen a hospital given a ' $P$ ' approval (Provisional) with the hope that the local authority would provide the finance necessary to implement some of the recommendations. This finance was not forthcoming, and as certain recommendations could not be implemented (in particular the formation of new posts), the situation in which the Approval Team found the hospital on its return visit led to the award of a ' $U$ ' category (Unapproved). 